\title{
Autoria coletiva, autoria ontológica e intertextualidade: aspectos conceituais e tecnológicos*
}

Antonio Miranda

Doutor em ciências da comunicação.

E-mail: cmiranda@unb.br

Elmira Simeão

Doutora em ciência da informação pelo CID/UnB.

E-mail: elmira@unb.br

\section{Suzana Mueller}

$\mathrm{PhD}$ in Information Science, Sheffield University.

E-mail: mueller@unb.br

\section{Resumo}

O texto levanta questões relacionadas ao fenômeno da autoria principalmente no contexto da comunicação extensiva e da perspectiva do pensamento complexo que norteia sua interpretação. Traz estudos sobre websemântica e a contribuição da ciência da informação para permitir conexões entre os conceitos de documentos da Web, com o pressuposto de que os textos autorais no futuro, sejam individuais ou em colaboração, poderão valer-se de recursos estruturadores tanto dos conteúdos, quanto na geração a priori de metadados e inter-relacionamentos. Em tabela gradativa, apresenta-se a distinção entre citação, intertextualidade, cópia autorizada, cópia não autorizada e o plágio, conceitos relacionados com a temática em questão, além da discussão sobre a multivocalidade, metodologia já aplicada em contextos acadêmicos.

\section{Palavras-chave}

Autoria. Autoria coletiva. Autoria ontológica. Intertextualidade, Multivocalidade.

\section{Collective authorships, ontological authorship and intertextuality: conceptual and technological aspects}

\begin{abstract}
The text seeks to raise issues related to responsibility, as a phenomenon, mainly within the context of extensive communication and on the perspective of the complex thought that guides its interpretation. Studies are carried out about web semantics as well as the contribution of Information Science which allows conceptual connections for Web documents, supposing that the author texts, in the future, either individualized or in cooperation, may use structured resources both for contexts and a priori generation of metadata and interrelationships. In a gradual table, distinction is made of citation, intertextuality, authorized copy, non-authorized copy, and plagiarized copy, concepts related to the present issue, in addition to the discussion about multivocality, methodology already applied in academic contexts.
\end{abstract}

\section{keywords}

Collective authorship. Citation. Multivocality. Intertextuality.
De meus plágios mais ou menos inconscientes, com tijolos alheios me edifico.

(Anderson Braga Horta)

\section{INTRODUÇÃO}

A autoria é uma instituição em crise. Analisando-a em perspectiva, é possível afirmar que está sujeita a interpretações diversas e até divergentes em níveis de conceito e de práxis, em uma abordagem multidisciplinar. Sempre esteve atrelada às noções de cultura e ciência em que se desenvolveu, mas é na civilização ocidental, sobretudo com o advento do liberalismo, do capitalismo e do individualismo triunfantes, que a autoria ganhou foros de direito e as áureas da sociedade. O estatuto do direito autoral configura-se como reconhecimento máximo legal e social do indivíduo autor como detentor de propriedade intelectual de valor econômico e de caráter hereditário. Várias pesquisas européias sobre economia da cultura demonstram que os benefícios do copyright em termos econômicos, no entanto, conforme aponta Canclini (2008), vão satisfazer muito mais os investidores que propriamente os criadores dos produtos culturais.

Obviamente a autoria não está restrita à propriedade intelectual de um texto - literário, científico, técnico, jornalístico - , mas a qualquer tipo de criação humana, da arquitetura à música, da fotografia às artes cênicas, com suas peculiaridades, características culturais e problemáticas próprias. Também pode ser compartilhada, dependendo do produto que revela e, legalmente, é um aspecto tratado de forma diferenciada entre os países latinos e europeus nos modos de interpretação dos direitos de propriedade. Canclini (2008) destaca, por exemplo, que a concepção jurídica predominante nos países latinos atribui propriedade intelectual ao criador das obras literárias, artísticas, musicais, audiovisuais ou científicas:

O direito anglo-norte-americano estabelece o copyright, noção centrada nos direitos de reprodução, que abrange um espectro mais amplo: gravações sonoras, emissões

\footnotetext{
* Esse artigo é uma versão atualizada de trabalho apresentado no Noveno Congreso Internacional de Humanidades, realizado na Universidad Metropolitana de Ciências de la Educación, Santiago (Chile), em outubro de 2006
} 
de rádio ou televisão, incluindo, ou tratando de incluir, os suportes digitais. Nos países onde ainda se reconhece a autoria pessoal, os direitos são concedidos aos escritores, que os vão transferindo para as empresas na medida em que a reprodução industrial das obras exija maiores investimentos (CANCLINI, 2008, p. 80)

Além das disputas individuais e da busca pela apropriação da originalidade, o direito legal de reprodução restrita se confronta com os avanços da tecnologia e as inúmeras possibilidades de reprodução e até deturpações de material disponibilizado em formatos digitais convencionais e não convencionais, com ferramentas de tratamento e disseminação que podem facilmente baixar arquivos e multiplicá-los infinitamente. Ao superarmos o modelo de reprodução em série (que parte de uma matriz gerando uma série)em uma comunicação dirigida às massas, próprio da indústria cultural que se expandiu na segunda metade do século passado, constatamos a possibilidade de apropriação de produtos em um processo de hibridez permanente que mistura linguagens e formatos e leva ao público segmentado resultados de uma criação de produtos culturais mutantes, alguns apócrifos.

Considerando assim a convergência tecnológica dos meios extensivos de comunicação (SIMEÃO, 2006) e a hibridez de elementos da criação na pós-modernidade, aparecem então os conflitos sobre o direito de propriedade e a concepção legal de produto cultural. No processo de comunicação em redes tecnológicas, descrito por Mendonça (2008) como a comunicação "Todos-Todos”, qualquer combinação de autoria é possível, não há proprietários absolutos, muito menos produtos culturais permanentes. Instaura-se então um território litigioso no processo de legitimação das autorias pela apropriação mais evidente de elementos de outras obras, reproduzidos em processo de fragmentação e "colagem”, que Maciel (2006) chama de fenômeno do "Ctrl C / Ctrl V" (corta e cola). Esse fenômeno dissolve não apenas fragmentos textuais, mas também áudio, imagens e símbolos, não somente estilos e metodologias de concepção, mas também idéias elaboradas em formatos que transformados repetidamente dificultam a identificação de sua origem e autoria.

\section{AUTORIA E PRODUÇÃO NA CIÊNCIA}

Há um aspecto relativo à autoria que também é polêmico. Na ciência, os textos lidos e revistos são transformados em outros textos, chamados revisões de literatura e estado-daarte de um tópico em pesquisa. Eles são valorizados sempre e quando haja o reconhecimento explícito das origens dos dados (texto, imagens etc.) com autoria comprovada e aceitável. $\mathrm{O}$ "corta e cola" para a montagem de uma revisão de literatura é permitido, desde que se façam todas as citações de forma correta. Dadas as referências citadas e o endereço de cada fonte como indicação importante para a investigação, o procedimento é legítimo. Isso autentica a produção acadêmica e ajuda a identificar autores com concepções conceituais semelhantes ou divergentes. As criticas devem, acima de tudo, preservar o diálogo e o crescimento da área do conhecimento em análise.

Mas o conceito de autoria principalmente no contexto da comunicação extensiva (SIMEÃO, 2006) e da perspectiva do pensamento complexo (MORIN, 2000) que norteia sua interpretação foge dos padrões biblioteconômicos convencionais. Podemos inferir também que na ciência os conceitos, mesmo os mais originais, são igualmente provisórios e falseáveis. Karl R. Popper, considerado um dos mais influentes filósofos do século XX a tematizar a ciência, foi grande defensor da democracia liberal e oponente implacável do totalitarismo. Ele e outros autores defenderam uma espécie de individualismo metodológico para contrapor ao totalitarismo de doutrinas antiindividualistas ou "holísticas" simplistas. $\mathrm{Na}$ teoria do conhecimento objetivo proposta pelo filósofo austríaco que cunhou o termo "racionalismo crítico" para descrever suas concepções, o conhecimento será sempre conjectural e provisório.

Tradicionalmente a exacerbação do individualismo está no primado do direito autoral absoluto, em que o autor é reconhecido e protegido pelo depósito legal de seus manuscritos assinados e reproduzidos por qualquer meio, questão que escapa ao interesse central do presente artigo. É difícil reconhecer o quanto uma obra é "original" para certificar sua autoria, além da forma ou formato em que está escrita ou concebida*, composta ou escrita de alguma maneira. O reconhecimento costuma ser mais pacífico quanto ao formato em que foi produzido do que na idéia mesma, na originalidade que a concebeu, embora teoricamente seja complexo separar forma e conteúdo ou, como diria McLuhan, meio e mensagem. A frase famosa "Penso, logo existo", atribuída à René Descartes (1596-1650), filósofo, cientista e matemático francês, conhecido como "o pai da filosofia moderna", tem a mesma idéia e foi dita, com outras palavras: "Pois o mesmo é pensar e ser”, pelo poeta pré-socrático Parmênides, que viveu no período 530-460 a.C.

O processo de inscrição das idéias com palavras e imagens (representações) é dialético.Voltando às concepções de Popper, há sempre um raciocínio lógico que, embora coerente em seu encadeamento, está fundamentado em idéias apenas prováveis e, por esta razão, traz a possibilidade

\footnotetext{
"Para entender os conceitos de tipo, formato, conteúdo e suporte de um registro informacional, consultar o artigo de Miranda e Simeão (2002). Disponível em http://

www.dgz.org.br/ e http://www.antoniomiranda.com.br/ ciencia_informacao/art_dg_zeroartigo.pdf
} 
de sofrer uma refutação. Para Peirce, citado por Elias (2004, p. 59), trata-se de um "grafo existencial" que relaciona interioridades com exterioridades, mediante um conjunto de relações signaléticas, capazes de representar sinteticamente (parcialmente) um fenômeno. Tal representação, comumente expressões gráficas, pode ser inscrita, por exemplo, em suportes como a mente, o papel, o monitor, etc. (ELIAS, 2004, p. 59), mantendo sempre uma relação com representações anteriores.

"Os grafos revelam-se, pois, no interior dos sistemas de signos, perfazendo etapas de modelizações de percursos que vão da experiência individual aos processos coletivos de cultura" (ELIAS, 2004, p. 60).

Seria possível separar autoria da representação em que ela se manifesta? No caso do texto, é mais fácil identificar a redação do que as idéias que ela expressa. O plágio é mais reconhecível textualmente do que conceitualmente, para dizer que a maneira como se diz estaria mais protegida do que aquilo que se diz propriamente (Descartes versus Parmênides). A perífrase ou circunlóquio são formas legítimas de sintetização de textos e idéias alheios até mesmo sem reconhecer as autorias quando as idéias já estiverem no domínio comum e de difícil reconhecimento. Mas também existem as técnicas cientificas que examinam textos escritos à mão ou à máquina para descobrir se são autênticos ou falsificados, se foram escritos por uma mesma pessoa ou não, buscando seu executor, em uma ação que não interessa diretamente a esta análise.

É óbvio que o processo de criação do texto científico, técnico e, em certos casos, o literário, (e sua metodologia de produção e composição) amplia ou reduz o "percentual" de sua originalidade, seja ele registrado em livro, em uma resenha, ensaio ou em uma tese. Estamos falando da "plasticidade" do texto, de seu formato e arquitetura onde a comparabilidade e o reconhecimento das expressões são mais identificáveis do que no domínio abstrato das idéias. Conseqüentemente, a "prova" do plágio se obtém pela comparação de frases literárias, notas, versos, trechos coincidentes mais do que pelo que expressam. É difícil separar a idéia de sua formulação textual (ou pictórica, ou audiovisual etc.). Hoje dispomos de programas e instrumentos para checar textos e atestar, com relativa facilidade, a sua origem quando desconfiamos de sua autenticidade ou autoria. Â medida que avancemos para uma "biblioteca universal" do conhecimento registrado em livros e monografias de todo tipo (disponibilizados na

\footnotetext{
* $\mathrm{Na}$ tentativa de buscar as possíveis origens da poesia visual, considerando que em 2006 estamos completando 50 anos do surgimento do Manifesto da Poesia Concreta, deparamos com autênticos exemplos de pioneirismo em poetas greco-latinos e do Renascimento, desde o século III a.C e século XVI, culminando com os caligrammes de Apollinaire do início do século XX. Ver exemplos em: http:// www.antoniomiranda.com.br/poesia_visual/poesia_visual.html
}

Web), a tarefa de traçar as similitudes de textos e as "origens" das idéias estará facilitada, dando acesso a uma espécie de DNA de textos para sua certificação de origem*.

A literatura científica, sempre eivada de citações e modelos teóricos e metodológicos de contexto, teria ainda mais dificultada a identificação do que seria verdadeiramente "original" e único de um texto determinado. Daí que o plágio repousa quase sempre na imitação do formato e/ou na cópia óbvia de textos alheios sem citação, ou seja, indevidamente apropriados, como veremos adiante.

Em sentido contrário, espera-se que o autor do texto científico demonstre familiaridade com os textos e as idéias alheias, no processo de "revisão de literatura" e até da adoção de teorias e metodologias (explicitadas na "metodologia científica") no desenvolvimento da pesquisa. É um território de sutilezas, um ritual de devoções a idéias, autores e métodos consagrados. Uma liturgia institucionalizada pela academia, pelas sociedades científicas e pelas publicações científicas, filosóficas e artísticoliterárias. Em certa etapa pretendeu-se hierarquizar os níveis de originalidade de um texto acadêmico. Tentou-se separar o que seria uma revisão de literatura própria de uma dissertação de mestrado de um verdadeiro estado-da-arte adequado para uma tese de doutorado, tarefa que resultou de difícil reconhecimento e aplicação, considerando a natureza mais técnica ou teórica das pesquisas.

O vício do "corta e cola" ou "Ctrl c / Ctrlv" (MACIEL, 2006) é recursivo em sentido positivo ou negativo, na produção de textos, ou seja, quanto à sua origem e autoria, considerandose a fantástica proliferação de produtos. Para Maciel, a divulgação de notícias no ambiente jornalístico se beneficia dessa disseminação e é prática comum no uso de releases pela Internet na imprensa em geral. A intertextualidade, a hipertextualidade e a autocitação — quanto às autorias autenticadas - são cada vez mais reconhecidas e consagradas como recursos para a agregação de valor aos textos, dependendo da capacidade do produtor no manejo de técnicas próprias de resumo, copidescagem, editoração.

Citar corretamente, parafrasear, reescrever textos ou reapresentar idéias alheias conforme os cânones e normas vigentes é um mérito da produção de um tipo específico de texto*. Pode até mesmo multiplicar-se

\footnotetext{
" Os problemas de citação não se atrelam apenas ao "formato" e ao "conteúdo" de um registro de origem, mas também aos seus outros elementos, notadamente ao seu "tipo". Sempre citamos o caso do professor que avaliou negativamente um trabalho final de disciplina em que o aluno fez citações de grandes autores em apoio à sua tese, mas cometeu o deslize de "misturar" indevidamente os tipos de documentos citados. Entre artigos científicos de comprovado nível de criação e originalidade (presumida), o aluno citara também algum artigo jornalístico de menos valor científico; ou seja, o tipo de documento predispõe, em algumas situações, a sua reconhecibilidade.
} 
mediante citações como notas de rodapé, valer-se do apud e congêneres e até de recursos da hipertextualidade dos índices remissivos, das referências cruzadas, citações de citações.

Notadamente, na composição de páginas web em html que permite os links de deslocamento entre textos (que não é o mesmo que intertextualidade). Pelo menos, no campo da literatura científica, exigem-se múltiplas citações diretas e indiretas, a apropriação de textos e idéias alheias na montagem de um novo texto como parte de sua elaboração, como ingredientes ostensivos de originalidade e ineditismo. Originalidade e ineditismo, portanto, são fenômenos que, por si só, merecem estudos mais aprofundados.

\section{NOVOS PARADIGMAS DE AUTORIA E EDIÇÃO: A ONTOLOGIA E A WEBSEMÂNTICA}

Teatro, cinema, fotografia e qualquer outra forma de expressão artística e técnica participam do processo criativo e de autoria com os escritores de textos literários e científicos, ou, em uma acepção mais hipertextual, de produtos híbridos e multidimensionais. Mesmo os programas desenhados para a produção de textos - o Word 2003 e o LaTex, entre outros - permitem a instrumentalização da produção textual combinada com imagens, sons etc., embora centrados na produção, edição e difusão de literatura. No entendimento de Oliveira, refere-se a um "novo paradigma de produção" onde "os autores deverão desempenhar tarefas de estruturação do conhecimento com os quais eles ainda não estão familiarizados." (2006, p. XX).

Fernando Pessoa dizia que não se escreve com idéias, mas com palavras, pretendendo dizer que as palavras é que moldam as idéias. Tristan Tzara, o revolucionário dadaísta, deu um exemplo curioso da inversão no processo criativo. Ordinariamente, o criador parte de sua experiência para construir seu discurso com as palavras e outros signos que considera válidos para a representação das idéias. Tzara recortava palavras de textos alheios, jogava os pedaços de papel em um balde e depois, aleatoriamente, ia construindo novos e inusitados textos... idéia aparentemente incoerente. Na atualidade, a autoria se vale de ferramentas que vão revelando textos e palavras sob rígido controle que norteiam o processo criativo por meandros imprevisíveis. A websemântica e as ontologias constituem alternativas a serviço dos autores no processo de redação de textos simultaneamente com a própria pesquisa.

A tese de Oliveira versa sobre a questão da websemântica e a contribuição da ciência da informação para permitir conexões semânticas entre os conceitos de documentos da Web e assim interligar as idéias do texto pelo que elas representam e não limitar-se apenas a como foram escritas, como é ainda o procedimento de indexadores e buscadores automáticos.

Sistemas baseados em ontologia para a representação da informação e autoria na Websemântica estão surgindo e provendo soluções como anotação semântica, extração da informação, marcação ontológica, etc. (...) especialmente se desejarmos dar apoio a autores no desenvolvimento de conteúdos mais bem estruturados e representados, a partir do potencial que têm as atuais tecnologias baseadas em ontologias (OLIVEIRA, 2006, p. 7).

Oliveira vai mais longe ao pretender a construção de uma série de requisitos e um modelo de arquitetura de ambiente de autoria baseada em ontologia para a websemântica. Parte do pressuposto de que os textos autorais no futuro, sejam individuais ou em colaboração, poderão valer-se de recursos estruturadores tanto dos conteúdos, quanto na geração $a$ priori de metadados e inter-relacionamentos, e não a posteriori como acontece tradicionalmente. Em outros termos, os novos autores-editores já criam seus textos de conformidade com estruturas ontológicas, além das semânticas correntes, que facilitam seu tratamento automático, área de interesse da ciência da computação, da lingüística e da ciência da informação em estudos de arquitetura da informação:

As ontologias parecem árvores de conceitos, em que cada folha é um termo específico relacionado a um galho que é um conceito mais geral. Serve para mostrar, por exemplo, que manga é uma fruta tropical, e não manga de camisa, num dado contexto. (OLIVEIRA, 2006, p. 15).

Os textos superam sua linearidade e se tornam hipertextuais, mediante links explícitos e implícitos como no caso da websemântica:

Assim, a representação semântica dos documentos pode ser feita durante o processo de autoria, e não apenas depois do documento ter sido publicado (...) destacandose a navegação conceitual para recuperação da informação com base na relevância e pertinência dos conceitos contidos em documentos, além dos processos correntes de representação da informação (indexação, marcação, anotação, etc.) (OLIVEIRA, 2006, p. 16-17).

Estaríamos diante de uma autêntica "autoria ontológica". Certamente que essa metodologia implicaria transformações no ciclo produtivo, que parte da escolha de dados, passa pela estruturação semântica e iconográfica de informação, por sua vez relacionadas em uma estrutura complexa de conhecimentos na qual o novo modelo de representação agregaria valor ao processo. Em uma etapa 
final, a autoria seria mais "inteligente" no sentido de sua construção e projeção social mediadas pelas novas tecnologias da informação. Exemplificando, os novos autores não partiriam apenas das próprias experiências e reflexões pessoais, mas ampliariam isso valendo-se dos recursos informacionais disponíveis em rede, assim também e sobretudo pela capacidade de gerar conhecimento novos pelas relações desenvolvidas no processo produtivo com as ferramentas de autoria.

$\mathrm{Na}$ prática, significa aliar a autoria do texto com o processo de pesquisa de fontes de informação durante o processo de redação e produção com a ajuda da ontologia. O referido processo englobaria quatro modos cognitivos: o de rede, que permite inter-relacionar termos e descobrir conteúdos semelhantes e relacionados; o de árvore, usado na estruturação hierárquica do próprio documento, e ainda o modo editor, padronizado, e o modo de texto, para a navegação e edição de blocos de textos, entendendo-se autoria como um sistema mais complexo do que a escrita.

O novo ambiente de publicação eletrônica vem mudando drasticamente a forma com que as pessoas produzem conhecimento e conseqüentemente na forma com que elas disponibilizam esse conhecimento por meio dos documentos. Isso está refletido no aparecimento de um conjunto de funcionalidades para a autoria de documentos que ainda não está muito claro para todos (OLIVEIRA, 2006, p. 23-24).

Ou seja, o texto deixa de ser linear e ganha as facilidades do hipertexto, com a plasticidade do html, do pdf, do $\mathrm{xml}$, do rdf etc.

\section{AUTORIA E A ANÁLISE DE REDES SOCIAIS}

Em artigo recente, Silva (2006) pretendeu aplicar o método de análise de redes sociais (ARS) no estudo da co-autoria no Programa de Pós-graduação em Ciência da Informação da Universidade Federal de Minas Gerais. O autor partiu dos conceitos de Wasserman e Faust (1999) sobre o método e focalizou o período que vai de 1997 ao final de 2004, considerando a implantação do doutorado na instituição, tido como um marco no desenvolvimento da produção científica em análise. Queria o autor do artigo coletar dados sobre a produção científica local, partindo da premissa de que uma "uma rede densa de artigos em co-autoria indica a execução de um programa de pesquisa vigoroso, com resultados obtidos a partir da colaboração dos professores" (SILVA, 2006, p. 185) e, em segundo lugar, "a colaboração entre os professores de diferentes linhas indicaria uma relação próxima entre as diversas disciplinas que influenciam a área" como pressuposto para a consolidação de pesquisas interdisciplinares. Escolheu como produção bibliográfica os trabalhos completos em eventos e artigos completos publicados em periódicos registrados no Sistema CV. Lattes da plataforma Lattes no ano de 2005.

No final, Silva constatou que o número de artigos em coautoria entre professores do programa cresceu pouco mais de quatro vezes, enquanto foram multiplicados por 30 aqueles com alunos orientandos. Estas parcerias múltiplas parecem ser uma tendência, ou seja, os orientadores estariam incentivando os alunos na produção de textos durante a elaboração de teses e dissertações e também depois da defesa, na condição de co-autores, assumindo a criação conjunta da obra, "por conta da avaliação ao qual é submetido e para concorrer ao financiamento de projetos de pesquisa, dentre outras coisas" (SILVA, 2006, p. 187)*.

Entre as conclusões, verificou-se haver "uma forte concentração da produção conjunta em torno de poucos professores, e que a rede de colaboração entre professores é relativamente esparsa" (SILVA, 2006, p. 187). A rede de co-autoria estudada contém artigos com dois ou mais autores. O total de 23 professores nas 15 linhas de pesquisa proporcionou um potencial de 253 pares de coautoria, mas apenas 28 foram verificadas (densidade de $11 \%)$, constatando-se um baixo nível de cooperação, tanto dentro quanto fora das linhas de pesquisa.

Sem pretender discutir aqui os resultados específicos do estudo, é importante afirmar que

a ciência da informação é, normalmente, apresentada como uma área de conhecimento das ciências sociais com características marcadamente interdisciplinares, mas cada uma das linhas possui uma interdisciplinaridade distinta. Assim, dentro dos Programas, essa organização deveria contribuir para atrair professores com diferentes formações que, por meio da realização de pesquisas e da colaboração entre eles, pudessem avançar na construção do campo da ciência da informação (SILVA, 2006, p. 191).

O que não está comprovado na prática. A ciência da informação vem se hasteando em princípios bibliométricos no processo de mensuração e análise do fenômeno da autoria**

\footnotetext{
* Ver trabalho sobre normas de co-autoria na resolução 006/ 2005 de 10 de agosto de 2005 disponível em http:// www.ailha.com.br/pospsico/docs/006/2005.doc

** Alfred Lotka (1880 - 1949), químico, ecologista, demógrafo e matemático, ficou conhecido na área de bibliometria a partir de um artigo pouco representativo de sua obra. Ele mostrou que o número de autores com $\mathrm{n}$ publicações em uma bibliografia pode ser descrito como uma lei de potência da forma â $\mathrm{k}$ C / . Ele demonstrou que â tende para $2 \mathrm{e}$, nesse caso, $\mathrm{C}$ seria igual a $6 /(ð) 2$, ou seja, aproximadamente 0,61. Assim, se uma bibliografia pode ser descrita por essa lei de potência, $61 \%$ dos autores teriam contribuído com apenas uma publicação. Ver: http://users. pandora.be/ronald.rousseau/html/lotka.html
} 
De fato, existe um grupo reduzido de professores que respondem pela maior parte da produção, e que a colaboração se dá, mais intensamente, entre professores de uma mesma linha de pesquisa, ou seja, em vez de uma colaboração interdisciplinar, embora haja colaboração entre uma parte deles situados em diferentes linhas (SILVA, 2006, p. 192).

Por fim, destaca-se que o uso da ARS permite análise mais aprofundada da colaboração entre os professores, destacando fatos que não seriam detectáveis com o uso de métodos estatísticos tradicionais.

\section{SCIENCE COMMONS - NOVOS MODOS DE COLABORAÇÃO NA CIÊNCIA}

As inúmeras e crescentes possibilidades tornadas realidade pelas tecnologias da informação vêm modificando hábitos de acesso e uso da informação em todas as áreas de atuação, na música, artes, lazer, educação e agora também na ciência, como atesta a emergência de movimentos recentes como o Creative Commons (http:/ /creativecommons.org/) e, mais especificamente, o Science Commons (http://www.sciencecommons.org/).

A questão da autoria coletiva na ciência difere em vários aspectos da autoria coletiva em outras áreas da cultura, como na música, em textos literários, ou nas artes. Para Canclini (2008), aspectos de autoria podem ser compreendidos mais amplamente, em conceitos que associam a propriedade de bens culturais ao autor "pessoal" de uma produção literária, científica ou artística, através da autoria comercial, que se apropria dos direitos de reprodução de originais para movimentar empresarialmente esta produção e, de forma mais ampla, da autoria coletiva:

Os antropólogos acrescentam este terceiro tipo: a autoria coletiva ou comunitária, própria da produção artesanal musical e festiva das sociedades em que a comunidade, e não os indivíduos, considera-se agente criador (CANCLINI, 2008, p.81).

A autoria coletiva na ciência é sui generi, conforme explicado anteriormente. $\mathrm{O}$ motivo está no papel que o reconhecimento da autoria desempenha na ciência (certificação do conhecimento) e na vida do pesquisador: mais do que o lucro financeiro, está em jogo o seu nome. Para entendermos o quanto o prestígio do nome significa para um pesquisador, poderíamos fazer uma analogia com o que a credibilidade da moeda representa para a economia de uma nação, ou os bens pessoais para um indivíduo. Assim, é essencial para a sobrevivência profissional de um pesquisador ter a autoria de suas produções científica validada e reconhecida pelos pares. $\mathrm{O}$ reconhecimento do valor da contribuição científica se dá com a publicação e se firma pela citação ao texto publicado por outros pesquisadores.

Por isso, chama tanto atenção a emergência, no campo da ciência, da possibilidade da autoria coletiva progressiva. A novidade agora é a possibilidade e a vontade de disponibilizar um texto científico ou trabalho didático e até mesmo os dados coletados para uma pesquisa, para que desconhecidos, mesmo sem contatos prévios, possam utilizá-los para construir algo diferente a partir dele. Para uma área de atuação que depende do reconhecimento da autoria (regida por relações hierárquicas), é algo surpreendentemente inovador.

A novidade trazida pelo Science Commons se realiza por meio da dispensa, pelo autor, do direito autoral tradicional (todos os direitos reservados), representado pelo símbolo Ó e pela adoção do princípio proposto pelo Creative Comum (alguns direitos reservados), devidamente ancorado no sistema legal do país onde ocorre e representado pelo símbolo (c). A prática atual cumprida por qualquer pesquisador que tenha seu trabalho aceito em revistas científicas nacionais ou internacionais exige que o autor ceda seus direitos autorais à revista, permanecendo com ele apenas direito moral sobre os conteúdos. Seu "ganho" vem do prestígio de ter publicado e das citações recebidas, que elevarão seu nome na hierarquia da ciência, abrindo-lhe as portas para financiamentos, convites, prêmios. Com o Creative Commons o autor permite o reuso, interferência mesmo, em seu texto de uma forma mais livre e legal, preservando, se quiser, o direito do reconhecimento da autoria sobre o original.

O movimento Science Commons tornou-se possível após a implementação de iniciativas ligadas ao acesso aberto e ao auto-arquivamento. Como esses, foi estimulado pelo que se considera um exagero de barreiras legais ao acesso e ao uso de conhecimento científico publicado, interpostas pelas editoras das principais revistas científicas e algumas instituições de pesquisa. O Science Commons se origina na crença que o desenvolvimento científico está diretamente ligado à possibilidade não apenas do acesso, mas também do uso e reuso, livre e legal, da informação científica, inclusive o direito de transformá-la (The NeuroCommons Project, s.d.). De acordo com responsáveis pelo movimento, o Science Commos tem como objetivo promover inovação na ciência por meio da redução dos custos legais e técnicos do compartilhamento do trabalho científico. Pretende possibilitar a remoção de obstáculos à colaboração científica por meio da criação voluntária de regimes legais para a pesquisa e desenvolvimento (Wellcome to ScienceCommons. s.d.). 
Embora a adesão de pesquisadores ao movimento Sciense Commons ainda não pareça significativa no que se refere a conteúdos resultantes de pesquisa publicáveis em revistas indexadas de prestígio, parece estar crescendo para outros tipos de produção, especialmente ligados à educação científica. $\mathrm{O}$ movimento vem crescendo em vários países, inclusive no Brasil.

O Sciense Commons não é a única iniciativa visando à autoria coletiva em áreas ligadas a ciência e ao ensino. Outro campo muito promissor é o de iniciativas de educação a distância. Por exemplo, Matta (2003) descreve questões relativas a ambiente de construção e autoria coletiva na educação à distância, definindo-os como

ambientes que permitem o exercício da autoria coletiva e do trabalho do groupware, compreendido como o conjunto de sujeitos construtores de conhecimento de uma certa comunidade de práxis.

A tecnologia está presente, permitindo contato entre sujeitos separados pela distância física.

\section{AUTORIA E INTERAÇÃO DE IDÉIAS, QUAIS OS LIMITES?}

É consenso que a construção de uma idéia se pauta pelo conhecimento que o autor tem de assuntos relacionados a ela. O problema é saber qual o limite que qualquer indivíduo deverá observar na apropriação de um conhecimento que lhe é anterior. Dentro do contexto da comunicação científica, por exemplo, os critérios são mais rigorosos, como já comentamos anteriormente. Em outras áreas e atividades, no entanto, um texto (ou outro produto cultural) tem mais valor agregado quando é disseminado, e não há preocupação com a autoria, muitas vezes ela é até desconsiderada, o objetivo é a popularização das idéias. Há casos de produções culturais que são originalmente resultado de um trabalho de modificações de uma produção original. A autoria depende assim da movimentação com produtos de outros autores. Destaca Canclini:

Além das discrepâncias sobre quando deve prevalecer a propriedade intelectual ou a comercial, a atribuição da autoria, baseada no também polêmico conceito de originalidade, tem sido questionada por teóricos da literatura e das artes, pelos próprios artistas e escritores, desde Duchamp e Borges, até os DJs e os artistas recicladores que pós-produzem a partir do trabalho dos outros (CANCLINI, 2008, p.81)

QUADRO 1
Buscando elucidar essas considerações acerca do conceito de autoria, apresenta-se a seguir um quadro de interrelações possíveis para a apropriação de produtos culturais, tomando como referência o texto e considerando a capacidade dialógica de seu produtor e as combinações e incorreções que podem existir na relação com idéias de outros autores e suas manifestações dentro de uma escritura.

A “CITAÇÃO”, segundo aponta a NBR 10520, norma estabelecida pela Associação Brasileira de Normas Técnicas (ABNT), é a menção de uma informação extraída de outra fonte. Por ser considerada de efeito legitimador no texto científico, notadamente, a citação deve ter seu indicativo priorizado na fase de elaboração e revisão do trabalho acadêmico. $\mathrm{O}$ autor do texto citado também deverá ser mencionado, junto com outras fontes, ao final de cada capítulo, ou no final do trabalho (referências, NBR 6023) acadêmico (livro, artigo etc.).

Os formatos de apresentação de citação variam conforme fonte e a disposição do autor do texto em esclarecê-las corretamente no documento. A norma brasileira é bem explícita quanto às possibilidades de variação, considerando o tipo de documento citado, sua origem e possíveis combinações. As imprecisões e incorreções na tarefa de citar, no contexto da comunicação científica, desvalorizam o texto acadêmico, podendo até colocar seu autor e o trabalho sob suspeita.

Considerando o recurso da citação, destaca-se a citação direta como sendo aquela que apresenta textualmente, muitas vezes entre aspas (recurso abolido recentemente na própria norma), os dizeres (textos publicados em documentos reconhecidos) recolhidos de outro documento, seguido, entre parênteses, de autor, página e data do documento citado. As citações indiretas se mesclam ao texto do autor do documento, mas mantém limites bem claros; não só as idéias originais são evidentes, como também as expressões e termos utilizados para expressálas, seguidas de comentários outros que, estes sim, refletem o pensamento do novo autor e sua argumentação (contrária ou complementar) a idéia exposta. O recurso é muito utilizado, se observarmos que, na maior parte dos

Inter - relações de autores e idéias dentro do texto

\begin{tabular}{|l|l|l|}
\hline 1 - Citação & Direta & Indireta \\
\hline 2-Intertextualidade & Concordante & Discordante \\
\hline 3-Cópia autorizada & Integral & Modificada e concordante \\
\hline 4-Cópia não autorizada & Integral & $\begin{array}{l}\text { Modificada e discordante ou } \\
\text { concordante }\end{array}$ \\
\hline 5- Plágio/ Pirataria & Integral & Modificado \\
\hline
\end{tabular}

Ci. Inf., Brasília, v. 36, n. 2, p. 35-45, maio/ago. 2007 
casos utilizamos as idéias apenas para ajudar a construir um argumento novo, o que de já pode ser considerado o início de uma intertextualidade.

\section{AUTORIA E COMUNICAÇÃO: ENTRE CITAÇÕES, INTERTEXTUALIDADES E A CÓPIA}

A "intertextualidade”, segundo aponta o dicionário Michaelis, é o processo de produção de um texto literário que parte de vários outros e com eles se imbrica*. Essa expressão é aplicada na literatura e na educação para conceituar "um fenômeno constitutivo da produção do sentido e pode-se dar entre textos expressos por diferentes linguagens" (SILVA, 2002). Seguindo este raciocínio, Silva, focando o contexto da educação e sua natureza pedagógica, lembra que professores devem ter consciência e investir na idéia de que os textos não são puros, e o discurso de qualquer autor é, na verdade, um diálogo com algo já escrito ou falado por outrem.

Na enciclopédia Wikipédia (http://pt.wikipedia.org/wiki/ Intertextualidade), a intertextualidade é explicada como uma técnica de superposição de um texto (literário) a outro, ou "a influência de um texto sobre outro que o toma como modelo ou ponto de partida, e que, às vezes, provoca uma certa atualização ou modernização do primeiro texto". A obra cita o caso do livro Mensagem, de Fernando Pessoa, que retoma com o poema "O Monstrengo" o episódio do Gigante Adamastor de "Os Lusíadas" de Camões.

"Discurso de citações" (MOUILLAUD, 1997, p.118) é assim que o teórico francês define, no contexto do jornalismo, os textos de um jornal. Cada vez mais preocupado com a disseminação estratégica das informações, os periódicos diários, antenados com as particularidades da massmedia, distanciam-se dos enunciados originais dos entrevistados (e fontes) para alinhavar fatos e atos, particularizando um texto e dando a ele um contorno de notícia para um públicoalvo definido. Esse fenômeno da adaptação de textos a uma situação que se quer evidenciar como mais importante é uma técnica comum nas ciências sociais, particularmente, onde a subjetividade é um aspecto mais notável nos textos, se comparado à objetividade das ciências exatas e da natureza. A diferença é que na ciência a comunicação sobre a origem de uma idéia é obrigatória e no jornalismo, nem sempre.

\footnotetext{
* A noção de intertextualidade foi introduzida na Teoria Literária por Julia Kristeva em 1966 por influência da noção de dialogicidade que M. Bachtin havia desenvolvido no seu livro Estética da Palavra. Ver em http://sescsp.uol.com.br/sesc/ convivencia/oficina/livrovivo/intertextualidade.htm
}

No percurso de produção da notícia, o jornalista, também escritor de um texto que brota a partir de outros autores consultados (fontes), é o responsável pela invenção e descoberta da idéia nova e esta pode ter várias feições. Entre os diversos meios e gêneros informativos da massmedia, muitas diferenças, incluindo as editorias onde o profissional se encaixa e seu local de trabalho, poderão modificar a noção de autoria e intertextualidade. Os releases, por exemplo, são montados em assessorias de imprensa, de relações públicas ou publicidade, com a intenção de serem literalmente copiados (total ou parcialmente). Neste texto, há uma visão do ponto de vista da instituição e por isso sua natureza jornalística pode ser relativa, conforme defendem Rabaça e Barbosa (1987). Uma assessoria de comunicação se valoriza à medida que suas notícias são divulgadas por outros jornalistas em cópias autorizadas ou edições não autorizadas que mantêm as idéias e formulações inicialmente construídas mesclandose às mensagens de vários veículos com assuntos de editorias diferentes. Rabaça e Barbosa chamam a atenção do problema de copiar o release literalmente, destacando que o repórter deverá observar a realidade dos fatos, complementando o release com dados realmente completos. Neste percurso, a autoria já se dissolve entre o profissional da assessoria e o do veículo. Fica permitida a cópia total do release, a proliferação de textos editados por diversas editorias a partir de uma mesma cópia dando ao texto muitas versões, a princípio não autorizadas formalmente, já que as assessorias não podem ter controle algum sobre o processo de reprodução.

A “CÓPIA AUTORIZADA", portanto, neste contexto, seria uma ação jornalística de edição e adaptação de textos. Eles são modificados ou adaptados para valorizar idéias (atos ou fatos), sem necessariamente considerarem a questão da autoria. No caso das agencias de notícia, as cópias autorizadas e editadas são notáveis na opinião de Moillaud. Em muitos casos esta ação não é diferente dentro do contexto da comunicação científica, já que autores tentam dar voltas diante de discursos para formular, em essência, enunciados que repetirão os dizeres de outros com um novo conjunto de palavras. Há de se constatar um rigor maior na origem e citações de enunciados para determinados contextos, considerando a comunicação científica (na saúde, por exemplo).

Mouillaud (1997) destaca a diferença entre o discurso de um periódico (reescrituras), enquanto uma instância editorial definida e tratada circunstancialmente (aquela composta de textos vindos de agências de notícias e que são apropriadas pelo jornal), e o discurso das citações (as fontes usadas na elaboração de um texto) mencionadas nas diversas matérias produzidas e assinadas pelo repórter. 
A citação, diferenciando-se dos enunciados que trás, respeita-lhe a forma. A intertextualidade, apagando a enunciação dos mesmos, assimila seus conteúdos. Esta diferença de tratamento corresponde a uma diferença entre os termos da troca. Com os enunciados de agência, a mídia é um cliente - e tudo ocorre como se o pagamento do justo preço lhe permitisse (segundo a definição do código civil) o uso como um abuso (MOUILLAUD, 1997, p.118)

$\mathrm{O}$ tratamento dado aos textos das agências é revelador desta arquilocução do jornalismo e sua dúbia posição acerca da questão da autoria. Para o jornal, o enunciado do repórter é um discurso outro que compõe a informação do jornal como um produto agregado com destaque (assinado). Já a informação de agência, como outras que não têm assinatura, foi gerada como um produto (fornecido em partes acertadas de um contrato, como no caso das agências) e torna-se material diluído nos formatos de notícias atribuídas somente ao jornal (o autor), sem nenhum pudor. Os textos são intertextos de um mesmo senhor (o jornal) que poderá assumir a autoria de atos e fatos do real produzidos pela agência ou dará o devido crédito.

Disto resulta que a distinção entre os dois tipos de enunciados (o discurso estratégico e a informação) e os dois tipos de locutores (as fontes e os agentes) não designam conjuntos com limites precisos, mas conjuntos fluidos cujas fronteiras são incertas (MOUILLAUD, 1997, p. 120)

Para Mouillaud (1997), o jornal se apropria dos despachos das agências, deforma sua construção e mostra a tendência dos veículos de comunicação de massa ao tratarem abusivamente enunciados dos quais não são autores como se fossem seus, na medida em que modificam expressões, assumindo a autoria dos textos (editados), que na verdade são enviados por uma contratada. A prática não é a mesma quando se fala de fontes consultadas para a produção de notícias pelos repórteres, estes sim autores de textos originais em forma e conteúdo.

\section{INTERTEXTUALIDADE E PLÁGIO, QUAIS OS LIMITES?}

Liliana Christoff (1996), em tese de doutorado, discutiu a problemática do plágio em textos escritos pela visão da lingüística, tomando como base a questão da intertextualidade. A autora considera que "não são muito claros os contornos definidores do que seja plágio" e que é preciso "considerar os vários enfoques da noção de intertextualidade, bem como cotejar esta com o plágio".
Ao analisar o trabalho de Christoff, Carvalho destaca que a tematização do plágio implica como legítima a noção de propriedade literária. É ponto pacífico que "um texto é constituído por outros textos e um autor nasce de outros autores". Mas, no sentido legítimo do termo, o autor é alguém dotado de originalidade e que não perde seu vínculo social em seu discurso, ou seja, tornará legítima a autoria desde que expresse algo de novo considerando os conhecimentos adquiridos.

Daí a autora desenvolver seu trabalho na dimensão da autoria e do sujeito do texto, ou seja, aquele que não é fonte nem origem de conhecimentos, mas autor de um produto lingüístico, um sujeito que lê, seleciona e analisa conhecimento prévio; um sujeito que é ponto de convergência de outros textos, de outros discursos, jamais origem do saber. (ANTONIO LUIZ LOPES CARVALHO. Intertextualidade e plágio - questões de linguagem e autoria. http://www.unitau.br/prppg/publica/ humanas/download/intertextualidade-N2-2992.pdf)

Christoff elucida conceitos fundamentais (como sujeito de discurso, sujeito de texto, retextualização) para facilitar a distinção entre intertextualidade e plágio, por meio da identificação de "modalizadores" que são expressões reveladoras de que o texto (plagiário) seria uma mera cópia. Essa tarefa de investigação tem cunho interdisciplinar, mas é de competência do lingüista, que, dentro do método de Christoff, desenvolve uma perícia detalhada "O plágio ocorre a partir de um trabalho de dissimulação de intertextualidade". Mesmo sendo rigorosa, a autora conclui que em muitas áreas, como a geografia e a história, onde os textos são muito repetitivos, sem espaço para criação, há dificuldades maiores para tal análise. E nesse contextos ainda há muita discussão sobre os direitos autorais e os prejuízos causados pelas tecnologias. Para Levacov (2000, p. 268), a tecnologia de produção de documentos digitais desenvolveu-se mais rápido que os instrumentos legais para sua proteção.

\section{AUTORIA E AS NOVAS TECNOLOGIAS}

Leão (2001) vê a noção de autoria ganhar novos contornos com as tecnologias de informação e comunicação (TIC). Para esta autora, o computador e as diversas ferramentas que possui, associados à aplicativos que promovem a interatividade, acabam transformando o leitor em agente ativo no processo de construção de um texto, como ocorre nos e-books com capítulos independentes, ou documentos que geram esquemas conceituais.

O leitor é o criador de um percurso narrativo, que não precisa limitar-se a uma linha só de raciocínio "Ele 
(leitor) é um operador de multiplicidades" (LEÃO, 2001, p.45). O tradicional esquema (triangular) "autor, obra e leitor” é rompido em um processo circular, dinâmico. Em algumas obras hipermidiáticas, equipes inteiras trabalham na elaboração de um produto que não pode ter somente um autor. Leão destaca que, para muitos estudiosos como Landow (1992), a hipermídia marca o fim da autoria individual quando o autor sofre uma erosão do self, com a transferência do poder autoral para o leitor, em um processo que dissolve papéis tradicionalmente demarcados "O texto eletrônico se apresenta por intermédio de suas dissoluções. Eles são lidos onde são escritos e são escritos ao serem lidos" (JOYCE, apud LEÃO, 2001, p.43).

Para Levacov (2000), a questão que se coloca com as TICs é de como equilibrar os interesses contraditórios de editores e usuários no acesso aos documentos. Algumas conseqüências são previsíveis, como a substituição da arte da tipografia pela arte iconográfica e a dissolução da barreira entre o bibliotecário e o editor. Nesse caso, os originais de um documento se desprendem de uma única matriz para desdobraremse em milhares de cópias e a possibilidade de agregar valor aos textos e trabalhar também a sua customização é uma tendência no momento.

Levacov também destaca a dissolução da barreira autor/editor, com a possibilidade da eliminação total do editor. Os autores podem produzir e distribuir amplamente seus documentos, sem qualquer mediador ou obstáculo comercial. Nesta mesma lógica também as bibliotecas podem valer-se de textos diretamente dos seus provedores (pessoais ou institucionais), possibilitando aos usuários o acesso rápido aos documentos.

Segundo aponta Miranda (2005), a mudança de paradigma da comunicação intensiva para o da comunicação extensiva, acelerada pela recente montagem de uma fantástica infra-estrutura de informatização, gerou uma reengenharia das atividades produtivas da organização social, baseada em redes e conexões cada vez mais abrangentes e interoperáveis. O conhecimento coletivo é construído via TICs em bases inter e transdisciplinares, em uma multivocalidade de autorias. Em linhas gerais, esta multivocalidade pode ser compreendida, segundo apontam Miranda e Simeão (2006), como a possibilidade de um texto (ou qualquer outro trabalho intelectual) ser elaborado a partir de contribuições de vários agentes que assumem a possibilidade de uma criação intertextual, em uma cadeia produtiva em que os autores podem vir de diferentes áreas, sem necessariamente compartilharem experiências ou relacionamentos. O que vale é a complementaridade de suas idéias no processo criativo de produção.

Artigo submetido em 17/08/2007 e aceito em 07/11/2007.

\section{REFERÊNCIAS}

BARCELLOS, Renata da Silva de. A intertextualidade e o ensino de língua portuguesa. Disponível em: < http:// www.filologia.org.br/viiicnlf/anais/caderno09. 02.html>. Acesso em: 2008.

CANCLINI, Nestor Garcia. Leitores, espectadores e internautas: coleção observatório Itaú cultural. [S.1.]: Iluminuras, 2008.

CARVALHO, L. A. Intertextualidade e plágio: questões da linguagem e autoria. Resenha sobre a tese de doutoramento de Liliane Christoff. Disponível em: $<$ http://www.unitau.br/prppg/publica/humanas/ download.intertextualidade $>$. Acesso em: 2008.

ELIAS, Eduardo de Oliveira. Os grafos existenciais. Prosa Uniderp, Campo Grande, v. 4, n. 1, p. 45-48, dez. 2004.

LEÃO, Lúcia. O labirinto da hipermídia: arquitetura e navegação no ciberespaço. São Paulo: Editora Iluminuras Ltda, 2001.158 p.

LEVACOV, M. Bibliotecas virtuais. In: MARTINS, Francisco Meneses; SILVA, Juremir Machado da (Org.). Para navegar no século XXI. 2. ed. Porto Alegre: Sulina/ Edipuccrs, 2000. 294 p.

MACIEL, Alexandre. Jornalismo control c control v: uso do release na comunicação da informação on-line. 2006. 133 p. Dissertação (Mestrado em Ciência da Informação) - Departamento de Ciência da Informação, Universidade de Brasília, 2006.

MATTA, Alfredo Eurico Rodrigues. Comunidades em rede de computadores: abordagem para a Educação a DistânciaEAD acessível a todos: teorias: aspectos teóricos e filosóficos. Disponível em: < http://www.abed.org.br/publique/ cgi/cgilua.exe/sys/start.htm? UserActiveTemplate = 3 esp\&infoid $=724 \&$ sid $=69 \& \mathrm{tpl}=$ printerview $>$. Acesso em: 30 jul. 2006.

MENDONÇA, Ana Valéria. A integração de redes sociais e tecnológicas: análise do processo de comunicação para inclusão 
digital. 2007. Tese (Doutorado em Ciência da Informação) - Programa de Pós-Graduação em Ciência da Informação da Universidade de Brasília, 2007.

MIRANDA, A; SIMEÃO. (Org.). Informação e tecnologia, conceitos e recortes. Brasília: Universidade de Brasília, 2005. (Comunicação da Informação Digital, 1). ISBN 85 $8813600-7$.

MORIN, Edgar. Da necessidade de um pensamento complexo. In: PARA navegar no século XXI: tecnologias do imaginário e cibercultura. 2. ed. Porto Alegre: Sulinas, 2000.

MOUILLAUD, M. O sistema das citações. In: MOUILLAUD, Maurice; PORTO, Sergio Dayrell (Org.). O jornal da forma ao sentido. Brasília: Paralelo $15,1997.589 \mathrm{p}$.

OLIVEIRA, Edgar Costa. Autoria de documentos para a web semântica: um ambiente de produção de conhecimento baseado em ontologias. 2006.219 p. Tese (Doutorado em Ciência da Informação) - Universidade de Brasília, Brasília, 2006.

POPPER, Karl Raymond. Conhecimento objetivo: uma abordagem revolucionária. Belo Horizonte: Editora Itatiaia; São Paulo: Ed. da Universidade de São Paulo, 1975. p. 151-179. (Espírito de Nosso Tempo, v. 13).

RABAÇA, C. A.; BARBOSA, G. G. Dicionário de comunicação. São Paulo: Editora Ática, 1987. 636 p.
SCIENCE COMMONS EXECUTIVE DIRECTOR. Position announcement: (by the) Science Commons Executive Director. Disponível em: <http:// www.library.yale.edu/ 1license/ListArchives/0503/ msg00995.html>. Acesso em: 28 jul. 2006.

SILVA, Antonio Braz de Oliveira et al. Estudo da rede de co-autoria e da interdisciplinaridade na produção científica com base nos métodos de análise de redes sociais: avaliação do caso do Programa de Pósgraduação em Ciência da Informação - PPGCI/UMG. Encontros Bibli, Florianópolis, n. esp., p. 179-194, 1음 sem. 2006. Disponível em: <http://www.encontrosbibli.ufsc.br/bibesp/esp_03/913_GT7_silva.pdf > . Acesso em: 2008.

SILVA, Maurício da. Repensando a leitura na escola: um mosaico. Niteroi: EdUFF, [s.d.]. Disponível em: < http:/ /www.filologia.org.br/viiicnlf/anais/caderno09. 02.html>. Acesso em: 2008.

THE NEUROCOMMONS project. Disponível em: $<$ http://sciencecommons.org/data/neurocommons $>$. Acesso em: 02 de jul. 2006.

WASSERMAN, Stanley; FAUST, Katherine. Social network analysis: methods andapplications. Cambridge: Cambridge University Press, 1999. 857 p.z

WELLCOME to ScienceCommons. Disponível em: <http://sciencecommons.org/>. Acesso em: 28 jul. 2006. 